\title{
Gutiérrez Haces, R. (2016). Gramática para profesores de español como lengua extranjera, México: CEPE/UNAM
}

Ma. del Carmen Koleff Osorio

El Centro de Enseñanza para Extranjeros (CEPE) de la UNAM está por cumplir 96 años; es la escuela con mayor antigüedad en México dedicada a la enseñanza del español como lengua extranjera. A lo largo de esos años las clases se han impartido con diferentes métodos, enfoques y auxiliares didácticos; algo muy valioso ha sido contar con el apoyo de diversos materiales y manuales realizados por profesores y profesoras del mismo centro.

Hace más de 25 años, en México, quienes elegíamos enseñar español a no hispanohablantes como opción profesional —una vez que concluíamos la licenciatura en Lengua y Literaturas Hispánicas - sólo podíamos recurrir a un útil pero sucinto manual elaborado por cinco experimentadas profesoras del CEPE'.

En el ámbito de la gramática del español es de todos sabido que existen muchísimas publicaciones importantes desde que el castellano -hoy español-surgió hace más de cinco siglos. Así, tenemos las gramáticas clásicas, la primera de Antonio de Nebrija, de 1492; las de referencia ineludible como las de la RAE; las pedagógicas o comunicativas, como la de Francisco Matte Bon; y las enciclopédicas, como la que coordinó y elaboró el distinguido especialista Ignacio Bosque. Todas publicadas en España y que remiten, deliberadamente o no, sólo a la variante peninsular del español.

La gramática, a decir de la propia autora "está en la mente de los hablantes nativos" (p. 11), pero teóricamente se ha establecido como el eje central de toda lengua, y es la que determina que una lengua sea una y no otra. Así, las variantes del español son claramente observables a nivel fonético y léxico y menos evidentes a nivel gramatical, pero el hecho de que este material haya sido publicado en México y realizado por una experta mexicana, constituye una peculiaridad digna de mencionarse.

Esta Gramática para profesores de español como lengua extranjera, según advierte la propia autora, está pensada para los estudiantes del Diplomado para profesores de español como lengua extranjera y para quienes desean enseñar español a extranjeros, pero inevitablemente subyace la variante con el mayor número de hispanohablantes nativos en la actualidad: la mexicana, la cual,

1 Cf . Cervera, A. et al. (1983). La enseñanza del español a no hispanohablantes, México: UNAM. 
además, está más estrechamente vinculada con las del resto de los países hispanohablantes del continente americano.

La autora acota que "el material contiene información teórica básica sobre los temas de un curso para profesores" (p.12), pero ofrece mucho más, ni es tan básica ni es simplemente sobre los temas de un curso para profesores; en esta Gramática para profesores de español como lengua extranjera hay una acertada conciliación de aspectos semánticos y pragmáticos, enlazados a un eje morfosintáctico; la cuidadosa organización con que se presentan, permite visualizar la gramática desde esas tres perspectivas a la vez. Además, el manual integra acertadamente clasificaciones gramaticales clásicas con enfoques actuales, lo cual permite categorizaciones más abarcadoras y útiles para la enseñanza del español orientada a no hispanohablantes.

El libro ofrece también ejercicios y autoevaluaciones para aplicar los acercamientos reflexivos que se presentan antes, con el fin de derivar explicaciones sobre aspectos gramaticales dirigidas a quienes están en proceso de apropiación del español. De esa manera, quien estudie y practique con el manual podrá ir logrando un desarrollo de su propia intuición lingüística, que le permitirá comprender, analizar y ofrecer respuestas a dudas gramaticales de índole diversa.

Los distintos temas gramaticales incluidos en esta Gramática para profesores de español como lengua extranjera van desde los constituyentes de la oración simple hasta las oraciones compuestas, pasando por la sintaxis de las clases de palabras: con especial atención en la clasificación semántica de los verbos y las funciones con las que se relacionan, más un apartado respecto al modo subjuntivo.

Esta Gramática sui generis constituye, entonces, un compendio de estudio de varios aspectos gramaticales específicos del español, dirigido a aquellos que en verdad tienen vocación por esta profesión ya que las principales preguntas y dudas de los estudiantes, independientemente de su lengua materna o de la metodología que se siga, son de gramática. Por eso, la misma autora señala que será muy recomendable hacer otras lecturas así como investigar sobre los distintos temas para poder solucionar dudas con fundamentos claros y bien razonados.

Quienes forman parte de esta nueva generación de docentes en español como lengua extranjera, así como los que continúan en el ejercicio de esta enriquecedora labor deben sentirse agradecidos de poder contar con este manual, el cual los motivará a seguir investigando a partir de lo que aprendan con el estudio y práctica de las actividades que se incluyen. Con toda probabilidad, muchas dudas, preguntas y cuestionamientos gramaticales que reciban de sus estudiantes van a hallar guía en este manual, el cual les facilitará ofrecer respuestas más claras, sistematizadas y completas. 